\title{
GARRA DE JAGUAR, BOTÃO DE CAMISA, CARTUCHO DE BALA: UM OLHAR SOBRE ARTE, PODER, PRESTÍGIO E XAMANISMO NA CULTURA MATERIAL KAINGANG
}

\author{
Ana Elisa de Castro Freitas ${ }^{1}$
}

\begin{abstract}
RESUMO
Este artigo focaliza um conjunto de objetos de grande significado para a compreensão do Uri/presente e do Waxi/passado Kaingang, cujas vias interpretativas são tecidas em diálogo com interlocutores indígenas. Tais objetos acessam novas chaves para os estudos que abordam a arte, o contato interétnico e a etnohistória dos processos coloniais vivenciados no sul do Brasil. Fabricados pelos Kaingang novecentistas, estes objetos lançam luz para uma mais sofisticada interpretação das manifestações estéticas que integram a cultura material kaingang nas cidades contemporâneas.
\end{abstract}

Palavras-chave: Cultura material Kaingang. Tropeirismo. Perspectivismo ameríndio. Arte e cidade.

\footnotetext{
${ }^{1}$ Doutora em Antropolgia Social pela UFRGS e docente do Departamento de Licenciatura em Artes da UFPR. E-mail para contato: anaelisa.freitas.ufpr@gmail.com
} 


\section{JAGUAR CLAW, SHIRT BUTTON, SHELL CASING: A LOOK AT ART, POWER, PRESTIGE, AND MATERIAL CULTURE IN SHAMANISM \\ KAINGANG \\ AbSTRACT}

This paper focuses on a set of objects of great significance for understanding the Uri/gift and Waxi/Kaingang past, whose interpretive pathways are woven into dialogue with indigenous partners. Such objects access new keys for studies on art, interethnic contact and the ethnohistory of colonial processes experienced in southern Brazil. Kaingang manufactured by nineteenth-century, these objects shed light to a more sophisticated interpretation of aesthetic manifestations that integrate kaingang material culture in contemporary cities.

Keywords: Material Culture Kaingang. Tropeirismo. Amerindian perspectivism. City and art.

\section{INTRODUÇÃO}

$\mathrm{E}$

ste artigo é parte de um amplo estudo antropológico que focaliza a presença Kaingang (Jê Meridional) em territórios situados na margem leste do Lago Guaíba, superpostos parcial ou totalmente pela cidade de Porto Alegre e suas paisagens ecossociais (FREITAS, 2005).

Tal estudo buscou compreender que elementos materiais e simbólicos são importantes para a configuração do pertencimento Kaingang a estes espaços e quais as condutas territoriais empregadas por pessoas e grupos deste povo indígena para convertê-los efetivamente em parte de seu território.

Trata-se de um estudo de caráter etnográfico que faz interface com os campos da etnologia, etnoecologia e etnohistória. Especificamente no campo dos estudos Kaingang, soma-se a pesquisas realizadas mais sistematicamente desde a década de 1990 (MOTA; NOELLI; TOMMASINO, 2000; TOMMASINO; MOTTA; NOELLI, 2004).

Neste artigo, optei por destacar um achado etnográfico de grande significado para a compreensão do Uri/presente e do Waxi/passado, cujas vias interpretativas são tecidas em diálogo com interlocutores kaingang. Tal achado acessa novas chaves para os estudos que focalizam a arte, o contato interétnico e a etnohistória dos processos coloniais vivenciados no sul do Brasil. 
Trata-se de um conjunto de colares que integram o acervo etnográfico do Museu Júlio de Castilhos, em Porto Alegre, e duas peças cerâmicas da Tradição Arqueológica Taquara (SCHMITZ et al., 2002), localizadas em sítios na bacia do rio das Antas. Fabricados pelos kaingang novecentistas, estes objetos lançam luz para uma mais sofisticada interpretação das manifestações estéticas que integram a cultura material kaingang nas cidades contemporâneas, equivocadamente sombreadas pelos estigmas da assimilação e da aculturação.

\section{RESSIGNIFICANDO O URI DESDE O WAXI}

De acordo com Kimiye Tommasino e Ricardo Cid Fernandes (2001), os territórios Kaingang no Rio Grande do Sul tinham como limites, no século XIX, a noroeste 0 rio Piratini, a nordeste 0 rio Pelotas e a sul as bacias dos rios Taquari, Caí e Jacuí. Considerando a trajetória de líderes kaingang no século XIX, Luis Fernando Laroque (2000, p. 125-151) inclui neste esquema a bacia do rio dos Sinos, os campos dos divisores de água entre os rios dos Sinos e Caí, área de atuação das unidades político-territoriais associadas ao cacique João Grande Nĩvo. A cidade de Porto Alegre, situada na margem leste do Lago Guaíba, se localiza justamente no desaguadouro destes grandes rios - Jacuí, Taquari, Caí e dos Sinos -, contribuintes da Bacia do Guaíba.

Em termos ambientais, os rios e suas matas ciliares são entendidos como corredores ecológicos através dos quais se dispersam e transitam elementos da fauna e da flora importantes na configuração da paisagem. A paisagem, cujos contornos são também produto das relações entre homem e espaço, é por sua vez elemento central na construção de pertencimento de um povo ao seu território. Diversas etnografias têm enfocado os deslocamentos humanos ao longo de bacias hidrográficas e 0 zoneamento de seus espaços pelas dinâmicas territoriais indígenas (FAUSTO, 2001; FREITAS, 2005; POSEY, 1987; TOMMASINO, 2002).

Em meu estudo, considerei a cidade de Porto Alegre como parte da porção sul do território Kaingang, tendo em vista a bacia hidrográfica como unidade ecogeográfica fundamental ao entendimento de territorialidades indígenas (FREITAS, 2005).

Antiga capital da província de São Pedro do Rio Grande do Sul e hoje capital do estado do Rio Grande do Sul, Porto Alegre representa, no imaginário Kaingang, um importante centro de poder dos brancos. Viagens até a cidade são realizadas por lideranças kaingang em negociação com as autoridades, desde meados do século XIX, quando em decorrência do Regulamento das Missões de 1845 e da Lei 
de Terras de 1850 foram criadas as colônias agrícolas e aldeamentos indígenas na bacia do Alto Uruguai.

A criação de tais aldeamentos pelo governo da província visava a liberar as terras situadas na região hidrográfica do Guaíba (bacias dos rios Jacuí, Taquari, Caí, dos Sinos e Gravataî) para o estabelecimento das colônias, constantemente atacadas, à época, pelos kaingang do grupo de Doble, Braga e João Grande (LAROQUE, 2000).

As viagens dos kaingang a Porto Alegre se intensificaram ao longo do século XX. Até a década de 1940, eram feitas a pé e ainda hoje estão na memória dos velhos. Com elas, seus chefes e acompanhantes buscavam a garantia das terras e resgatavam antigas promessas feitas pelas autoridades, muitas delas nunca cumpridas. Acampavam nos arredores da cidade, em áreas públicas, em fundos de campo, nas beiras das estradas, sob viadutos, aos moldes do que também acontecia no contexto de outros estados do sul do Brasil (MOTA, 2000; MOTA; TOMMASINO, 2002).

Durante os acampamentos faziam amigos (e inimigos), estabeleciam alianças fundamentais para os tempos vindouros. Desde pelo menos as primeiras décadas do século $\mathrm{XX}$, estas viagens incluíam o escambo e comercialização de cestos e balaios de taquara-mansa (vãn), cipó-guaimbé (kò mrür) e outras fibras vegetais (BALDUS, 1979).

Embora a presença Kaingang em Porto Alegre seja identificada ao longo de todo o século XX, foi a partir da década de 1980 que este movimento ganhou expressividade. À luz do novo campo de direitos instituído pela Constituição Federal de 1988 no Brasil, muitos kaingang passaram a residir nas cidades, constituindo diferentes níveis de organização sócio-política; alguns se tornaram intencionalmente diacríticos.

A reciprocidade na cidade inclui uma ampla rede de interlocutores, sem excluir as coletividades situadas nas terras indígenas. Ao contrário, o movimento para a cidade justifica-se em alguns casos como um "texto" dirigido justamente a esses coletivos e suas lideranças, sobretudo no caso dos grupos que se deslocaram em contextos de conflitos sócio-políticos.

Diversos motivos são arrolados pelos distintos grupos kaingang que saíram da situação de terra indígena para viver na região metropolitana de Porto Alegre, entre os quais se destacam as tensões sócio-políticas, culturais e ambientais vivenciadas nos reduzidos espaços das terras demarcadas. 
Nas narrativas dos mais diferentes interlocutores, cujas territorialidades incluem a margem leste do Lago Guaíba, há marcadores históricos recorrentes: a perda dos territórios ancestrais, o confinamento nas terras indígenas estatais, a chegada do SPI e do gado, a permanente invasão dos brancos nos limites demarcados, a devastação das florestas, a chegada da FUNAI e das máquinas, a crise das instituições do xamanismo (kujà/xamã), da chefia tradicional (p'aí mág/cacique) e dos modelos produtivos tradicionais (caça, pesca, coleta, roça), a imposição do modo produtivo do trabalho agropecuário (panelão, arrendo) e da monocultura de soja, a submissão dos caciques aos chefes de posto, a vigência da repressão em lugar da lei do índio fundada no respeito, o fortalecimento das igrejas, escolas e postos de saúde e o enfraquecimento das lideranças indígenas, 0 domínio do dinheiro, o crescimento das cidades, as perseguições, torturas e a criminalização do índio pela lei do branco. Neste contexto, os kaingang que vivem em Porto Alegre reconhecem em seu movimento para a cidade a busca de alternativas a este estado de coisas. Sem contradição e simultaneamente, referem-se à região da margem leste do Lago Guaíba como área de transição no contexto das paisagens que compõe seu amplo território imemorial, uma zona que liga as florestas do Planalto com as terras baixas do Litoral, limite do mundo, demarcado pela grande água sem margem/Goj kafã tĩu, o Lago Guaíba (FREITAS, 2005).

Trata-se de abordar as territorialidades Kaingang em operação na história, mas a partir de suas lógicas próprias de ocupação do espaço e de relação com as sociedades, a natureza e a sobrenatureza, reconhecendo que as dinâmicas dos grupos sociais pertencentes a este horizonte cultural Jê se organizam com base no parentesco e no domínio de grandes territórios, que incluem bacias hidrográficas completas.

No contexto interétnico de Porto Alegre, alguns kaingang acionam com vigor sua identidade indígena, através de manifestações estéticas que os tornam diacríticos, como o artesanato, o canto, a dança, a indumentária ritual. A principal exibição pública Kaingang neste sentido é o vãnh-grénb tu vãjé - canto e dança da vitória (FREITAS, 2005, p. 222-227).

A base econômica da grande maioria das famílias kaingang em Porto Alegre é a produção artesanal, comercializada principalmente nos espaços das feiras administradas pelo poder público municipal, sendo mais expressivas a do Brique da Redenção e a da Praça da Alfândega. Há ainda um espaço fixo destinado pelo Decreto Municipal 12.874/2000 "para a comercialização de artefatos indígenas produzidos pelas etnias Kaingangue e M'byá Guarani” de arte indígena em Porto 
Alegre: a Loja da Cultura Indígena, localizada no Mercado do Bom Fim (PORTO ALEGRE, 2000).

No conjunto destes espaços - feiras, ruas, lojas - muitos kaingang comercializam objetos em formas variadas - cestos, bolas, bicicletas, vasos, luminárias, balaios - produzidos a partir do manejo de um conjunto de espécies de cipós (mrür) coletadas nas florestas locais, e que integram um complexo sistema que articula cidade e floresta pela mediação da cultura Kaingang. Em termos etnoecológicos, este sistema ganha expressão na categoria mrũr jykre/cultura do cipó (FREITAS, 2005).

Outros adquirem contas, miçangas, sementes e penas nos atacados da cidade para produzir colares e pulseiras, misturando esses elementos com sementes coletadas nas florestas locais, trazidas de outras terras indígenas kaingang e mesmo de outras cidades, em vias de escambo e comércio que integram outros povos indígenas do Brasil e do exterior.

É justamente esta última classe de objetos, pelo caráter heteróclito conferido pelas peças de origem industrial, que está na base de um discurso que põe em questão a "autenticidade", "originalidade", "indianidade", "interesse" do artesanato kaingang para as cidades, estendendo o estigma aos próprios indígenas - ditos então "misturados", "aculturados", "civilizados", "desinteressantes". Amparado na imagem idealizada e colonial de índio e seus atributos de pureza, este discurso em sua dimensão interétnica é enunciado por ambulantes que compartilham o espaço das feiras com os kaingang, por agentes indigenistas, por pessoas da sociedade local, por gestores públicos municipais, entre outros. Em sua dimensão intraétnica, estes mesmos termos discursivos são acionados entre os próprios indígenas, como marcadores de diferenças internas à sociedade Kaingang.

Os discursos depreciativos da arte Kaingang em Porto Alegre entravam em contradição com minha perspectiva etnográfica e mobilizaram novas rotas de pesquisa. Foi necessário deixar temporariamente o Uri e travar uma viagem pelo Waxi, perseguindo a cultura material Kaingang à luz de suas próprias chaves epistemológicas, movimento para o qual elegi a boa companhia do p’aí/chefe Zílio Jagtyg Salvador (TI Nonoai - TI Lomba do Pinheiro/Porto Alegre), do kujà/xamã Jorge Kagnãg Garcia (TI Nonoai - TI Serrinha), do pesquisador Francisco Rokág dos Santos (TI Nonoai - TI Morro do 0sso/Porto Alegre) e da artesã Iracema Rã Ga Nascimento (TI Nonoai - Vila Jari/Porto Alegre), cujas perspectivas foram postas em diálogo com a arqueologia, a história e a etnologia ameríndia. 


\section{NAS TRILHAS DA CULTURA ATRAVÉS DO WAXI}

Pesquisando casas subterrâneas associadas à tradição arqueológica Taquara e às populações kaingang, o arqueólogo Pedro Ignácio Schmitz et al. (2002) levantam dados extremamente interessantes e que merecem ser trazidos ao campo etnológico. Trata-se de peças cerâmicas provenientes dos sítios arqueológicos RS-A-27 e RS-A-29, situados no divisor de águas entre os rios Quebra-Dentes e Refugiado, afluentes do rio das Antas, uma região coberta por floresta com araucária e localizada na rota das tropas:

Na parte externa da casa 4, janela 1 (sítio RS-A-27) apareceu um botão de cerâmica $(2,7 \mathrm{~cm}$ de diâmetro por $0,9 \mathrm{~cm}$ de espessura), com dois furos. No interior da casa 1 do sítio RS-A-29 foi recuperado um pé, fragmento de uma representação humana (boneca?), feito com a mesma argila, o mesmo antiplástico e queima do resto da cerâmica. Se indicam o contato com populações brancas e cópia de modelos, estes já estão absorvidos e produzidos em material e tecnologia nativos (SCHMITZ et al., 2002, p. 83).

Figura 1 - 1-7 formas da cerâmica, conjunto A. 8 pé de boneca. 9 apêndice em forma de seio. 10 botão de cerâmica.

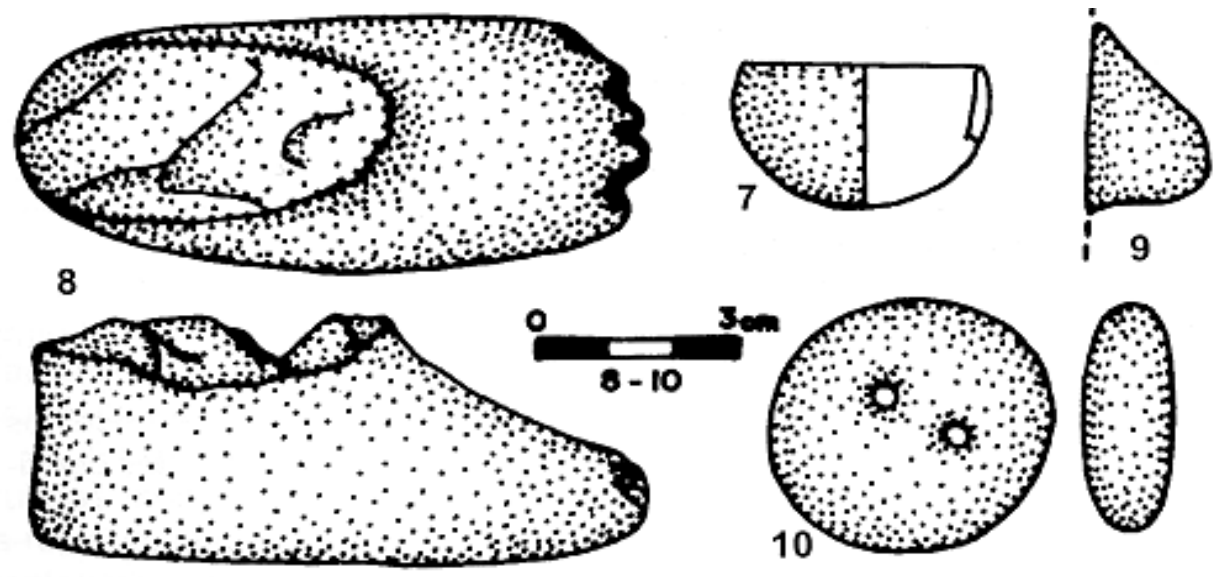

Fonte: Schmitz et al. (2002, p. 83). 
Como observam Schmitz e seus colaboradores, estes dois objetos indicam que os kaingang, nos séculos XVIII e XIX², experimentavam a reprodução de objetos da cultura material europeia empregando seus próprios repertórios culturais: a tecnologia cerâmica.

Outro conjunto de objetos aponta para este mesmo fenômeno - a abertura cosmológica Kaingang a símbolos, materiais e tecnologias alóctones: trata-se de colares confeccionados por chefes kaingang no final do século XIX e início do século XX e que integram o acervo etnográfico do Museu Júlio de Castilhos, em Porto Alegre.

Neles, os chefes kaingang arranjavam lado a lado materiais heteróclitos botões de camisa, fivelas, argolas de metal, cartuchos de bala, moedas, cordas e miçangas, provavelmente adquiridos nas frentes de contato com tropeiros, já nos primeiros povoados - e fibras vegetais, sementes, dentes, garras, cornos e conchas provenientes de seus distintos domínios territoriais: florestas, campos, lagoas, rios e $o$ litoral.

Figura 2 - Colares feitos com materiais heteróclitos
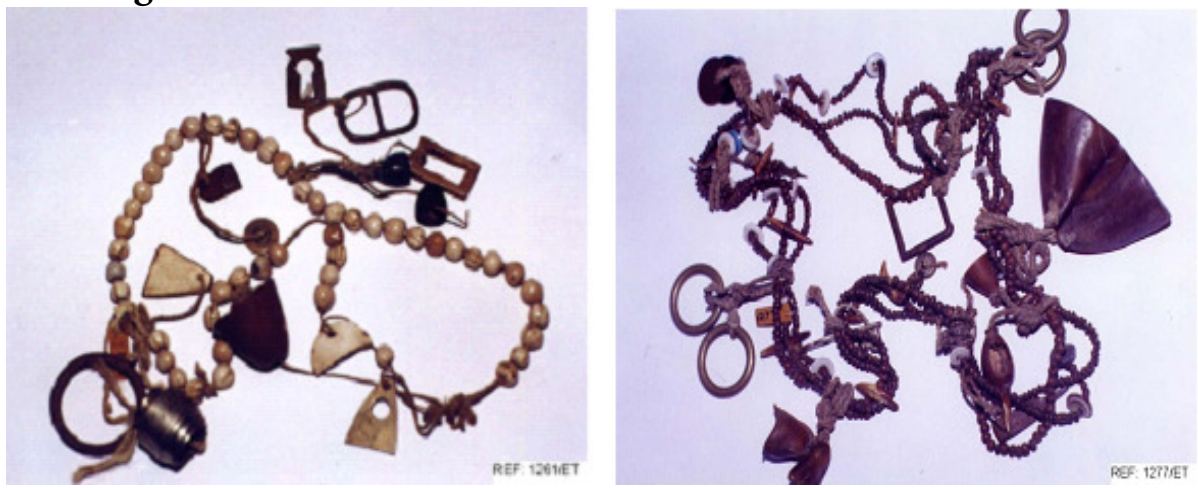

Fonte: Autora.

*Colares feitos com materiais heteróclitos, reunindo chifres, ossos, garras, dentes, sementes e fibras vegetais, junto como botões de camisa, cartuchos de bala, fivelas, argolas e algodão.

\footnotetext{
${ }^{2}$ As datações por Carbono-14 (C-14) e termoluminescência realizadas nos sítios em que estas peças foram localizadas remetem a ocupação aos séculos XVIII e/ou XIX (SCHMITZ et al., 2002).
} 


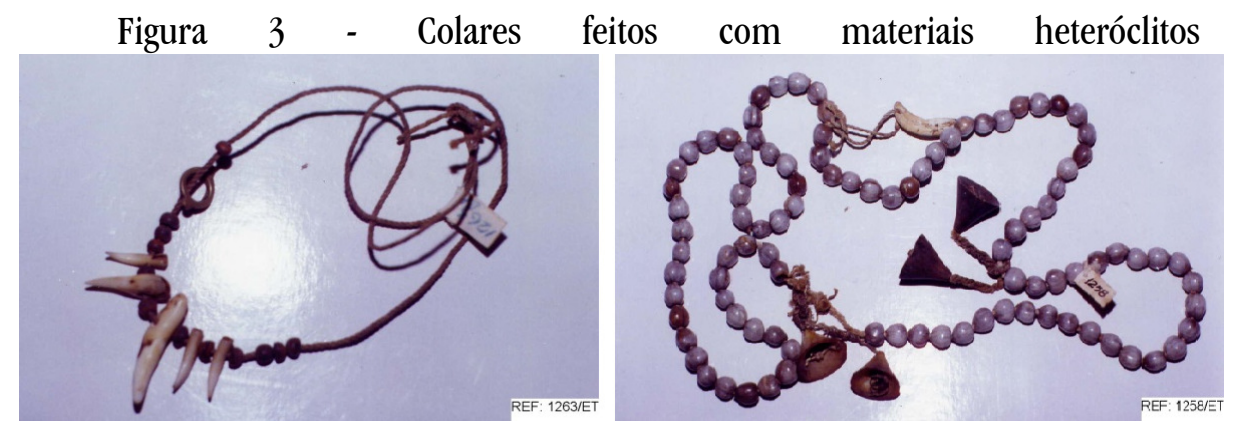

Fonte: Autora.

*De acordo com o interlocutor kaingang Francisco Rokág dos Santos, estes colares combinam chifres de veado (kãme), dente de cateto (ogxé) e sementes de capim (refy) - colar da esquerda -, assim como dentes de porco-do-mato (kràg), sementes de batinga e argola de metal colar da direita.

0 contexto histórico de produção dos colares e peças cerâmicas pelos kaingang novecentistas coincide com 0 avanço do processo colonial sobre 0 Planalto Meridional do Brasil, envolvendo acontecimentos que tiveram início na segunda metade do século XVII e primeira metade do século XVIII. Tal período foi marcado pelo interesse econômico das elites luso-brasileiras de Sacramento, Laguna, Rio de Janeiro e São Paulo pelo gado xucro que vagava livre nos campos do sul.

Apoiado em todo o panorama socioambiental e cultural da Bacia do Prata, fundou-se o ciclo do tropeirismo (PESAVENTO, 1984, p.13).

Primeiro, foi explorada intensivamente a Vacaria do Mar ${ }^{3}$, quando o caminho das tropas seguia pelo litoral, desde Sacramento até Laguna, percorrendo os territórios costeiros. No trânsito das tropas se estabeleciam os pousos, pontos de parada e de descanso (PORTO, 1954, p. 185).

Consolidada a exploração sobre os territórios do litoral, a pressão econômica sobre a Vacaria do Mar passou a exigir novas fontes de gado. Abriramse as rotas para a Vacaria dos Pinhais, no coração dos territórios Kaingang e Xokleng. Ali, nas florestas e campos, muitas parcialidades destes povos, empurradas pela ocupação litorânea, então se concentravam.

3 "Vacaria" é o termo que designa áreas de pousio do gado estabelecidas pelas frentes jesuíticas e integravam a economia das missões hispano-guaraníticas nos séculos XVII e XVIII no Rio Grande do Sul. 
Entre 1728 e 1730, Souza Faria realizou a primeira etapa do que ficou conhecido como o "Caminho da Mata". Esta estrada partia do Morro dos Conventos, no litoral do atual estado de Santa Catarina, atingindo os campos de São Joaquim, Lages e Curitibanos. Por esta estrada, Cristóvão Pereira transportou, entre 1730 e 1732, a primeira tropa pelo interior até Sorocaba. Este mesmo tropeiro abriu, em 1738, o "Caminho das Tropas", ligando os campos de Lages ao Rio Grande do Sul pela região da serra. Este caminho atravessava o passo de Santa Vitória, no rio Pelotas, atingindo as reservas de gado das Vacarias dos Pinhais, centralidade dos territórios Kaingang (LAROQUE, 2000, p. 50).

Cabe observar que, a cada novo modelo de investida colonial, modificavamse as condutas territoriais Kaingang adotadas para manter o controle de seus territórios ameaçados:

Os Kaingang souberam desde o primeiro momento tirar vantagens dos invasores, tais como roupas, utensílios e missangas, mas, ao perceberem que a intenção dos intrusos era a de se estabelecerem nos seus territórios, passaram a defendê-los violentamente através de ataques e mortes aos brancos até sua definitiva expulsão, ocorrida em 1774 (LAROQUE, 2000, p. 51).

Seja pela via do escambo, seja pela do assalto, estes indígenas adquiriam em suas frentes de contato com os luso-brasileiros objetos e tecnologias, novos símbolos dos estrangeiros que ingressavam em seus fluxos socioculturais autóctones, ganhando expressão na cultura material dos colares novecentistas e nos objetos cerâmicos descritos por Schmitz e colaboradores.

Estabelecida a via etnohistórica e arqueológica, cabe uma interpretação dos significados postos em jogo na parafernália de colares e peças cerâmicas dos chefes kaingang do século XIX. Para tanto, três pessoas tiveram uma contribuição especial: o p'aí Zílio Jagtyg Salvador, o kujà Jorge Kagnãg Garcia e o pesquisador e meu co-autor em outro estudo publicado anteriormente, Francisco Rokág dos Santos (FREITAS; SANTOS, 2007). Em momentos e lugares diferentes, entre abril e setembro de 2004 , estes interlocutores afirmaram que os colares (jãnka) são objetos de poder.

Na perspectiva do xamanismo do kujà Jorge Kagnãg Garcia, na medida em que um kaingang incorpora no seu jãnka/colar a garra ou o dente de um porcodo-mato (krág), de uma onça (mĩg), toma para si a força (tar) destes animais. 0 
mesmo vale para madeiras do mato $(k a)$ ou sementes $(f y)$, assim como para outros materiais. Considerando 0 domínio da floresta, 0 animal que simultaneamente mais fascina e atemoriza um kaingang, segundo Jorge Kagnãg Garcia, é a onça. Predador do homem, perigo iminente na floresta, a onça ou jaguar está presente em muitas histórias e mitos Kaingang.

Se, em algum momento de sua vida, um kaingang se deparar com a onça na floresta densa, e se porventura lutar e abater o animal, o feito torna-se sinal de grande coragem (jũmẽ) e força (tar). Para apoderar-se desta força, o kaingang deve tomar para si uma parte do corpo do felino - geralmente uma garra ou um dente - e integrá-lo em seus adornos corporais. Segundo Jorge Garcia, dentes e garras, assim incorporados, se tornam o veículo direto do poder ou força do jaguar dominado e apropriado pelo caçador/guerreiro kaingang.

Este mesmo princípio vale para penas de aves, conchas, sementes: 0 portador do colar (ou cocar) que integra estes materiais de certo modo carrega consigo os atributos dos animais e plantas originários. Nesta perspectiva, ao integrar objetos dos fog kupri - estrangeiros brancos - em seus jãnka, os antigos kujà e pa'í mág, os chefes kaingang, se apoderavam do poder destes estrangeiros.

Em acordo com Berta Ribeiro (1987, p. 17), pode-se considerar que "a representação dual homem-jaguar remete ao complexo de transformação do xamã em onça, recorrente na mitologia sul-americana”. Ora, o jaguar está presente no mito de origem Kaingang narrado pelo cacique Arakxó a Telêmaco Borba e exigiu estratégias especiais por parte dos heróis mitológicos Kamé e Kairukré para driblar a ameaça que representava (BORBA, 1904, p. 58-59).

Em seus estudos, Rogério Rosa (2005) sugere que o jaguar é um dos guias (jangré) mais poderosos no âmbito do sistema kujà do xamanismo Kaingang. A menção de Jorge Garcia ao emprego de presas e garras de felinos nos colares kaingang é sugestivo deste campo mitológico-xamânico de relação Kaingang com 0 jaguar e com a floresta. De outro lado, os cartuchos de bala e as moedas condensam simbolicamente os dois principais instrumentos empregados pela sociedade colonial no empreendimento da conquista dos territórios kaingang: as armas e o dinheiro. Na mesma perspectiva dos feitizeros que incorporavam símbolos cristãos em seus contextos rituais, estes chefes procuravam converter a seu favor o poder dos fòg kupri que os ameaçavam, através da incorporação dos objetos destes homens em seus colares.

Examinando em conjunto os materiais constitutivos dos colares dos chefes kaingang novecentistas, é possível identificar que em sua fabricação foram 
combinados elementos da floresta, litoral e campos com materiais da cultura colonial européia. Na perspectiva de Zílio Jagtyg Salvador,

\begin{abstract}
[...] 0 jãnka mostrava 0 quanto 0 cacique ou 0 pajé tinham andado, mostrava a valentia dele. Se ele usava uma concha, o outro dizia: 'olha, ele teve lá no mar'. Se ele usava o dente da onça, já dizia: 'olha, esse é valente mesmo! Brigou até com a onça!'. Já se ele usava uma bala de revólver, quem sabe eles pensavam: 'olha, esse aí é valente, não vou me meter com ele'. Se o colar era bem bonito, o dono dele era bem valente (Entrevista, Zílio Salvador, 2004)
\end{abstract}

A narrativa deste p'aí aciona uma perspectiva que permite reconhecer que os materiais agregados ao colar informam sobre os domínios territoriais Kaingang, depondo sobre a territorialidade de seu possuidor. Além disto, Zílio enfatiza ser 0 colar um meio de demarcar o poder e o prestígio do chefe perante seu grupo de pertencimento: "O colar mostra" - ou seja, é um meio de exibição e afirmação do status social de seu possuidor.

Em outras palavras, o poder da onça, do porco-do-mato ou do estrangeiro colonizador, materializado em adornos corporais, se confunde com o poder do próprio líder kaingang que dominou tais objetos. No colar, este poder é atualizado ao ser reconhecido pela sociedade.

Retomando Berta Ribeiro (1987), os objetos da cultura material de uma determinada sociedade exteriorizam ideias e conceitos. A análise destes objetos, com base no contexto cultural em que foram produzidos, permite decodificar ou interpretar seus significados. "Trata-se de estudar o conjunto da parafernália que identifica 0 indivíduo e o grupo como uma linguagem visual, um código, uma iconografia." (RIBEIRO, 1987, p. 15).

A respeito dos dentes de porco-do-mato (krág) presentes em um dos colares da coleção etnográfica do Museu Júlio de Castilhos (ref. 1263/ET), é fundamental reconhecer que este animal tem uma grande importância na etnoecologia Kaingang, como pude verificar em uma conversa com Jorge Kagnãg Garcia, em sua casa, em junho de 2004, na TI Serrinha, onde este kofã (avô, velho) residia com sua mulher, Maria Constante, e netos.

A viagem a TI Serrinha foi muito importante no meu campo etnográfico. Deu-se especialmente para o encontro com Jorge Kagnãg Garcia, mas não buscava apenas o sentido que este especialista conferia aos colares e adornos 
corporais dos chefes antigos, mas uma compreensão mais precisa a respeito da floresta e sua importância na ecologia Kaingang.

Permaneci hospedada na casa de Jorge Garcia por quatro noites. Todos os dias, por volta das cinco horas da manhã, céu ainda escuro, este kofã levantava-se e dirigia-se à cozinha de tábuas da antiga casa. Sentado em uma cadeira de madeira, Jorge Garcia acendia o fogo e em seguida começava a picar uma porção de fumo de rolo. Enquanto a conversa acontecia, ele amassava por longo tempo, na palma da mão, aquela porção de tabaco. A seguir, alisava uma palha de milho seca, onde acomodava e enrolava o fumo com cuidado. Então, com uma acha de lenha, acendia o cigarro dando duas ou três longas tragadas. Durante todo este ritual, que durava cerca de uma hora, Jorge Garcia falava da floresta.

Figura 4 - Jorge Kagnãn Garcia - Serrinha, Capinzal, 2003.
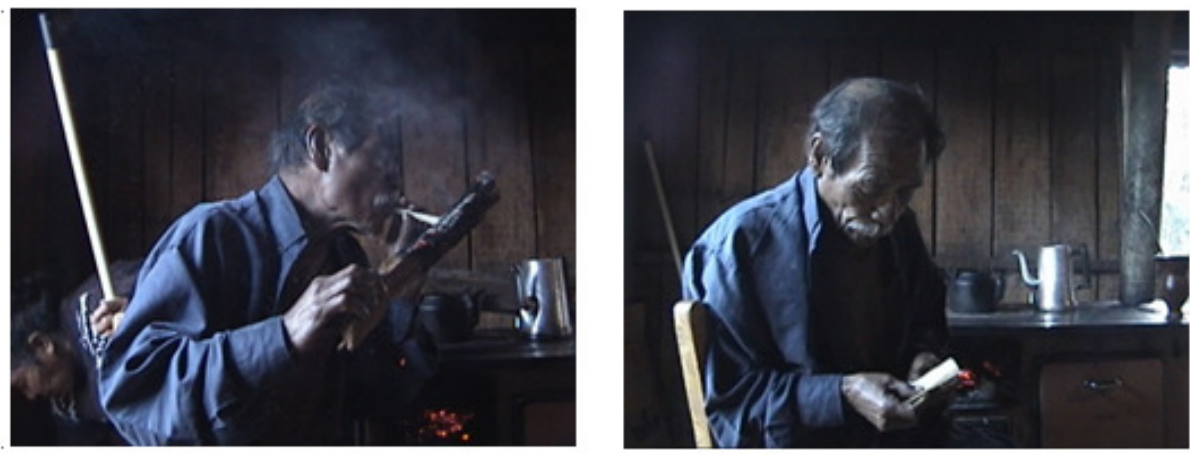

Fonte: Autora.

Foi numa destas manhãs que Jorge Kagnãg Garcia falou dos krág, os porcos-do-mato. Na perspectiva do xamanismo deste kujà, os porcos-do-mato se organizam em uma sociedade que em muito se assemelha à dos Kaingang: eles possuem caciques, guerreiros e xamãs.

Os xamãs dos porcos-do-mato são reconhecidos por sua habilidade em driblar os caçadores kaingang e suas estratégias só podem ser descobertas por poderosos kujàs. Para localizar e dominar as varas de porcos-do-mato, o kujà precisa vencer as versáteis camuflagens que estes animais adotam e que incluem 0 uso de remédios do mato. 0 consumo de remédios do mato pelos porcos-do- 
mato é sempre orientado por seus xamãs. Cabe ao kujà ludibriar o xamã dos porcos-do-mato para descobrir suas intenções.

Jorge Kagnãg Garcia conta que os xamãs dos porcos-do-mato e os kujàs kaingang perseguem-se mutuamente, na medida em que para ambos é vantajoso descobrir as estratégias do opositor. Utilizando remédios do mato indicados pelo seu guia animal - o jangré -, o kujà pode em sonho abordar o xamã dos porcosdo-mato e descobrir seus segredos. Desvendadas as estratégias do xamã dos porcos-do-mato, o kujà indica aos caçadores kaingang os locais onde os porcosdo-mato pretendem beber água, quais os pés de frutas que planejam comer e, assim, os caçadores obtém boa caçada.

Do mesmo modo, o xamã dos porcos-do-mato usa de camuflagens buscando descobrir, junto ao kujà, os planos de caça dos kaingang. 0 objetivo dos porcos-do-mato é desviar da rota dos caçadores e 0 intento dos caçadores é, efetivamente, interpelar os porcos-do-mato na floresta. De acordo com Jorge Kagnãg Garcia, uma vez localizada a vara de porcos-do-mato, cabe aos caçadores abater seu cacique. Trata-se de um animal diferente, com presas grandes, coloração mais escura e cheiro forte, em torno do qual se agregam todos os porcos-do-mato da vara. Veja-se este trecho da entrevista com o kujà:

Jorge Kagnãg Garcia - 0 cacique dos porcos é 0 cabeça deles. 0 cheiro dele é mais forte, as presas saem da boca por fora, a comunidade toda fica em torno dele. É a mesma coisa, o mesmo que os índios em volta do cacique deles. Quando o caçador mata o cacique dos porcos, eles ficam atordoados, sem saber o que fazer, então fica fácil pegar três, quatro, seis, a comunidade toda. Matando o cacique, tirando o cabeça, eles ficam que nem os índios sem liderança: um puxa prum lado, outro puxa pro outro e ninguém sai do lugar.

Pesquisadora - E o xamã deles, também é diferente?

Jorge Kagnãg Garcia - Também tem sua diferença, mas não como 0 cacique. 0 kujà deles tem 0 pelo bem lisinho, sem nenhum berne, nenhum machucadinho, porque ele conhece tudo o quanto é remédio do mato. Mas ele às vezes não tá junto na hora da caçada, é mais difícil de pegar, ele se aparta uns tempos da comunidade dele pra fazer 0 trabalho dele, é que nem os nossos kujà, a mesma coisa.

Pesquisadora - Então, na caçada, o alvo principal é o cacique?

Jorge Kagnãg Garcia - É o cacique. 0 caçador que pega o cacique já de pronto tira as presas dele. Aquilo ali é o poder. E tem partes que ele 
não pode comer, tem que deixar pros outros. Mas a presa é dele. (Entrevista, Jorge Garcia, 2004).

A caçada aos porcos-do-mato é um empreendimento coletivo. Estes animais são muito perigosos e não devem perceber o movimento dos caçadores. Jorge Garcia enfatiza que é o mesmo que uma guerra: tem que fazer o cerco sem que 0 bicho perceba, e sempre de olho no cacique deles. 0 caçador que abate 0 cacique dos porcos é reconhecido pelo seu grande feito, mas goza mais de prestígio do que de privilégios, haja vista que lhe é proscrita a ingestão de certas partes da caça. É justamente para demarcar este prestígio que ele confecciona seu jãnka (colar), que na guerra lhe dará a força do "cacique" abatido.

Jorge Kagnãg Garcia enfatiza que estas caçadas memoráveis ocorriam em um tempo em que a Floresta com Araucárias (Floresta Ombrófila Mista) estendiase desde a TI Serrinha até a TI Rio da Várzea, como um único matão. Efetivamente, trata-se das grandes e densas florestas que cobriam a região até 0 final do século XIX e as primeiras décadas do século XX.

Nesse tempo, que foi vivido por Jorge Kagnãg Garcia e povoa sua memória de evocações fabulosas, os Kaingang se pensavam como um povo da floresta e seu pertencimento a tal ecossistema se aprofundava na medida em que o matão era ameaçado pelo machado, pelas igrejas e pelo dinheiro, em suas próprias palavras.

Os campos eram cada vez mais cobiçados pelos colonizadores, que avançavam plantando cidades, como reconhece o kujà. Assim, os Kaingang retiravam-se aos poucos, nucleando-se nos refúgios das matas, embora se deslocassem até as vilas e cidades periodicamente para comprar sal, vender produtos da roça e artesanato. 0 mesmo ocorria com as populações animais da floresta: os fragmentos florestais remanescentes abrigavam diversas espécies da fauna, como os porcos-do-mato.

Jorge Garcia relata que, nas caçadas memoráveis dos tempos do matão, uma vez abatida uma vara e caso houvesse filhotes, estes eram levados pelos Kaingang à aldeia. Eram criados perto das casas, junto com as crianças. Se eram bem pequenininhos, uma índia assumia como se fosse um filho. As crianças conviviam com ele como se fosse outra criança (Entrevista, Jorge Garcia, 2004).

Quando este kofã relatou tal situação, recordei uma imagem marcante que havia visto na publicação $\mathrm{n}^{0} 88$ da Comissão Rondon. Trata-se de uma fotografia de Sophian Niebler, que documentou as expedições do indigenista Horta Barbosa (1947) quando este foi designado, na década de 1910, para empreender a árdua 
tarefa de "pacificar" os kaingang que atacavam os trabalhadores envolvidos na abertura de estradas de ferro no oeste paulista. Embora a imagem esteja em estado desgastado, optei por sua reprodução tendo em vista 0 valor etnográfico, endossado pela legenda do autor:

Figura 5 - Indigenista Horta Barbosa.

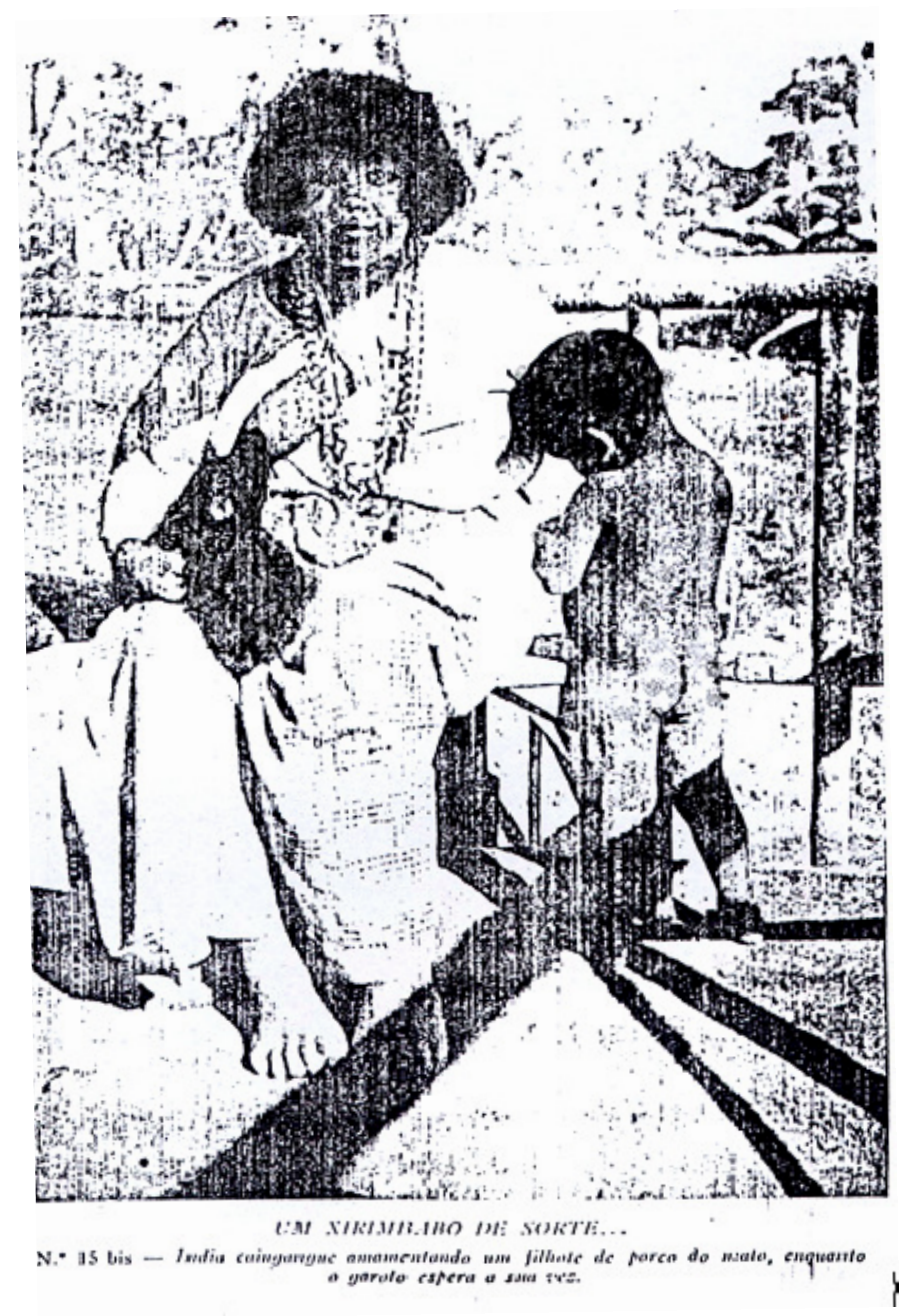

Fonte: Horta Barbosa (1947).

Fotografia: Sophian Niebler 
Cabe ressaltar que a amamentação é compreendida pelos kaingang como uma etapa fundamental na constituição da pessoa. De acordo com Iracema Rã Ga Nascimento, durante as muitas conversas sobre filhos que tivemos em sua casa na Vila Jarí, nos arredores do Morro Santana, Porto Alegre, ao amamentar a criança, a mãe ajuda a firmar seu espírito no mundo, e é isso que faz uma pessoa forte.

Esta mulher de 40 anos de idade amamentou todos os seus cinco filhos até que estes, por conta própria, deixassem de mamar. 0 ato de desmamar uma criança por imposição, segundo Iracema, resulta em uma série de doenças, não apenas para a própria criança, mas para a mãe, muitas delas do espírito e que só um kujà pode tratar. As crianças cujas mães lhes negam o peito crescem fracas, doentias, tristes, têm medo de tudo, são rebeldes e agressivas. De acordo com Iracema,

0 leite da mãe é um calmante natural. No leite tem todo quanto é tipo de remédio que a criança precisa. A gente também tem que se cuidar, tem que respeitar a dieta [resguardo pós-parto], tem coisas que não se pode comer, coisa muito forte, e também a gente se trata com ervas do mato. 0 leite da gente, antigamente, quando a gente tinha no mato todos os remédios que a mãe da gente indicava, era remédio pras crianças que se criavam fortes (Entrevista, Iracema Nascimento, 2004).

Iracema sempre manifestou grande estranhamento a respeito do modo como os brancos tratam as crianças - criadas longe das mães, em creches e escolas desde bebês. Nas feiras da cidade de Porto Alegre, onde vende artesanato acompanhada dos filhos, Iracema diz ter sido criticada muitas vezes pelos transeuntes por deixar suas crianças soltas, circulando, enquanto trabalha. Outras mulheres repetiram o mesmo reclamo, inclusive com relatos de ameaças de denúncia ao Conselho Tutelar, por deixarem seus filhos livres.

Segundo Iracema, um filho criado com os pais, que é amamentado e participa da vida cotidiana com as outras pessoas de seu grupo familiar, de sua comunidade, sabe perfeitamente como agir. Amamentar é, destarte, um ato de fundação sobre o qual se edifica a pessoa Kaingang em sua plenitude.

A combinação entre a narrativa do kujà Jorge Kagnãg Garcia, as conversas com Iracema Rã Ga Nascimento e a fotografia de Sophian Niebler permitem reconhecer que os porcos-do-mato, ao serem amamentados e trazidos do domínio da floresta para o domínio da casa e do espaço limpo da aldeia (CRÈPEAU, 2002), 
são reconhecidos em sua dimensão de pessoa e podem ser englobados socialmente pelos Kaingang.

De certo modo, os porcos-do-mato fornecem a chave para 0 reconhecimento da abertura social Kaingang à floresta, onde vivem muitas espécies de sujeitos - e não de objetos - que, aos moldes dos estrangeiros humanos, podem ser assimilados.

É fundamental considerar, à luz da etnologia, que a narrativa de Jorge Garcia a respeito da caça aos porcos-do-mato aproxima a cosmologia acionada por este kujà à perspectiva de outros povos indígenas sul-americanos (VIVEIROS DE CASTRO, 1996).

A antropóloga Tânia Stoltze de Lima (1996), em sua etnografia sobre os Juruna (Tupi) que habitam as ilhas do baixo-médio Xingu, trata dos encontros entre 0 xamã Juruna e 0 xamã dos porcos-do-mato, que igualmente se perseguem e desafiam, cada um buscando assumir a perspectiva de seu adversário e desvelar seus segredos. Na cosmologia Juruna, os porcos-do-mato podem mascarar inimigos e vice-versa, e caça e guerra confundem-se na perspectiva Jurura.

Durante as expedições em que Niebler fotografou a mulher kaingang amamentando o filhote de porco-do-mato, Horta Barbosa (1947) fez anotações a respeito das estratégias de caça adotadas pelos Kaingang para abater estes animais. Escreve Horta Barbosa (1947, p. 57): "Nas caçadas de porcos-do-mato usam os Kaingang cercar as varas que encontram; depois, apertando o cerco, investem contra os animais e os abatem a pauladas; nestas batidas é comum não lhes escapar uma única peça".

É importante observar que o varapau aparece nos relatos do engenheiro Pierre François Alphonse Booth Mabilde, que conviveu entre os Kaingang da gente de Braga e de Doble. Nos relatos de Mabilde, o varapau é referido como a arma predileta dos Kaingang nos conflitos entre grupos rivais, onde alvejavam a cabeça de seus inimigos (LAROQUE, 2000, p.142).

Sobre a caça, Horta Barbosa ainda dá a notícia de que "[...] é costume desses índios fazerem das caveiras das antas, dos porcos e macacos por eles caçados, espécies de rosários, ligando-as umas às outras por meio de cipós e pendurá-las, assim, em árvores ou no interior dos ranchos." (HORTA BARBOSA, 1947, p. 57).

É também Horta Barbosa (1947, p. 56) a informar que nos sepultamentos humanos os kaingang que viviam ao norte do rio Paranapanema costumavam decepar as cabeças dos cadáveres para serem enterradas somente depois. 
0 tratamento ritual de cabeças humanas e de espécies da caça também é via que aproxima a perspectiva cosmológica Kaingang das de outros povos ameríndios. É o caso dos Arara, um povo caribe que não é considerado xinguano nem norte-amazônico, que vive no vale dos rios Iriri-Xingu, nos interflúvios do Tocantins-Tapajós-Xingu, na mesma área cultural dos Juruna e outros povos Tupi, mas com intrusão Kayapó, e que traz prováveis influências de povos Jê do Brasil Central, ocupando por isso um lugar estratégico para a etnologia daquela região (TEIXEIRA-PINTO, 1997, p. 19-20).

Os Arara praticam um ritual denominado Iepari, associado à guerra de tocaia e captura de troféus humanos. No Iepari, partes das cabeças dos inimigos abatidos - escalpos, crânios, dentes e pele facial - se tornam troféus dos guerreiros Arara, ostentados como colares ou máscaras durante este ritual. Os Arara, aos mesmos moldes dos Kaingang paulistas, resistiram, na década de 1970 , aos projetos governamentais de desenvolvimento na Amazônia.

Por sua vez, a estratégia Kaingang de cerco aos porcos-do-mato, registrada por Horta Barbosa (1947), repete a performance do cerco guerreiro Kaingang ritualizado contemporaneamente no vãnh-grénh tu vãjé (canto e dança da vitória) (FREITAS, 2005, p. 222-223).

\section{O URI RESSIGNIFICADO}

Após esta viagem pela história, atravessando as evocações etnográficas estimuladas pela arqueologia, chega-se a alguns princípios da etnologia Kaingang, nos quais poder, prestígio, corpo, pessoa, floresta, arte, cidade são postos em relação em uma dimensão eminentemente perspectiva. 0 perspectivismo acionado pelo pensamento Kaingang posiciona os corpos dos guerreiros, dos caçadores, do kujà e do p’aí mág como meios de experimentação, domesticação e apropriação da força de animais e homens, assumindo seus poderes, força e prestígio através da objetivação de suas subjetividades.

Através do corpo, da in-corporação e da materialização objetiva dos colares, os Kaingang assumem simbolicamente o poder, a força e a dimensão subjetiva dos seres, pessoas e espíritos neles materializados. Esta agência lhes permite durar no mundo em que habitam.

A análise do conjunto de elementos apresentados, à luz da narrativa do kujà Jorge Kagnãg Garcia e da etnologia, possibilita reconhecer uma dimensão perspectiva no horizonte etnológico Kaingang, relacionada ao domínio da floresta (LIMA, 1996; VIVEIROS DE CASTR0, 1996). 
De modo complementar, todos estes eventos em conjunto permitem ver em operação a matriz cosmológica do dualismo Jê, visibilizada na abertura para 0 Outro/estrangeiro e na assimilação deste Outro em seus próprios esquemas culturais. Tal ponto de vista permite inverter a lógica da assimilação para uma perspectiva autóctone, em que o assimilado é o estrangeiro, e não ao contrário.

Revela também o esforço dos chefes kaingang em se apropriar do poder (sór) e força (tãn) dos estrangeiros (fôg) que ameaçam seus territórios: ao incorporar os símbolos destes estrangeiros em sua "parafernália" ritual, esses chefes confirmam sua posição de quem está no "centro das coisas", sustentando seu carisma e poder (GEERTZ, 1997, p. 187).

Tal matriz etnológica de incorporação do Outro pela via da cultura material, autorizada pelo dualismo Jê, oxigena a análise antropológica dos objetos que os kaingang põem em movimento, contemporaneamente, nas feiras e ruas das cidades.

A composição heteróclita dos objetos produzidos no Uri - conjugando sementes, missangas, penas, fibras, plástico - encontra sentido nos objetos produzidos no Waxi, e suas vias de circulação convidam para novas travessias etnográficas.

\section{REFERÊNCIAS}

BALDUS, Herbert. 0 culto aos mortos entre os Kaingang de Palmas. In:

Ensaios de etnologia brasileira. São Paulo: Nacional, 1979, p. 8-33.

BORBA, Telêmaco M. Observações sobre os indígenas do Estado do Paraná. Revista do Museu Paulista, São Paulo, v.6, 1904.

CRÉPEAU, Robert R. A prática do Xamanismo entre os Kaingang do Brasil meridional: uma breve comparação com o Xamanismo Bororo. Horizontes Antropológicos, Porto Alegre, ano 8, n. 18, p.189-209, 2002.

FAUSTO. Carlos. Inimigos fiéis: bistória, guerra e xamanismo na Amazônia. São Paulo: EDUSP, 2001.

FREITAS, Ana Elisa Castro. Mrũr Jykre: a cultura do cipó: territorialidades Kaingang na margem leste do Lago Guaíba, Porto Alegre, RS. 2005. Tese (Doutorado em Antropologia Social) - Universidade Federal do Rio Grande do Sul, Porto Alegre, 2005. 
FREITAS, Ana Elisa Catro; SANTOS, Francisco dos Santos Rokàg. 0 kujà e o sistema de medicina tradicional kaingang: "por uma política do respeito": Relatório do II Encontro dos Kujà, Terra Indígena Kaingang Morro do Osso, Porto Alegre, Rio Grande do Sul, Brasil. Cadernos do LEPAARQ, Pelotas, v. 4, n. 7/8, p. 201-239, 2007.

GEERTZ, Clifford. O saber local: novos ensaios em antropologia interpretativa. 4. ed. Petrópolis: Ed. Vozes, 1997.

HORTA BARBOSA, Luiz Bueno. A pacificação dos índios Caingangue paulistas: hábitos, costumes e instituições destes índios. In:

. O problema indígena do Brasil. Rio de Janeiro: Imprensa Nacional, 1947. Publicação n ${ }^{0} 88$ da Comissão Rondon.

LAROQUE, Luís Fernando da Silva. Lideranças Kaingang no Brasil Meridional (1808-1889). São Leopoldo: Instituto Anchietano, 2000.

LIMA, Tânia Stolze. Os dois e seu múltiplo: reflexões sobre o perspectivismo em uma cosmologia Tupi. Mana, Rio de Janeiro, v.2, n. 2, p. 21-47, 1996.

MOTA, Lúcio Tadeu; NOELLI, Francisco Silva; TOMMASINO, Kimiye (Orgs). As cidades e os povos indígenas: mitologias e visões. Maringá: UEM, 2000.

MOTA, Lúcio Taudeu; NOELLI, Francisco Silva; TOMMASINO, Kimiye. Urí e Wãxí: estudos interdisciplinares dos Kaingang. Londrina: UEL, 2000.

MOTA, Lúcio Tadeu; TOMMASINO, Kimiye. As cidades e os Kaingang no Paraná provincial. In: REUNIÃO BRASILEIRA DE ANTROPOLOGIA, 23., 2002, Gramada. Anais... Gramado: ABA, 2002.

PESAVENTO, Sandra Jatahy. Historia do Rio Grande do Sul. 3. ed. Porto Alegre: Mercado Aberto, 1984.

PORTO, Aurélio. História das missões orientais do Uruguai: segunda parte. Porto Alegre: Livraria Selbach, 1954. Coleção Jesuítas no Sul do Brasil, v. IV.

POSEY, Darrel Addison. Manejo da floresta secundária, capoeiras, campos e cerrados (Kayapó). In: RIBEIR0, B. (Org.). Suma Etnológica Brasileira: etnobiologia. Petrópolis: FINEP/Nozes, 1987. v. 1

PORTO ALEGRE. Prefeitura Municipal. Decreto n. 12.874, de 08 de agosto de 2000. Destina o uso da loja $n^{\circ} 22$ do mercado do bom fim para a comercialização de artefatos indígenas produzidos pelas etnias Kaingangue $e$ M'Byá-Guarani. Porto Alegre: 2000. 
RIBEIR0, Berta G. A linguagem simbólica da cultura material. In: RIBEIR0, Darcy. (Org.). Suma Etnológica Brasileira: arte índia. Petrópolis: FINEP/Nozes, 1987. v. 3 .

ROSA, Rogério Reus Gonçalves da. Os kujà são diferentes: um estudo etnológico do complexo xamânico dos Kaingang da Terra Indígena Votouro. 2005. Tese (Doutorado em Antropologia Social) - Universidade Federal do Rio Grande do Sul, Porto Alegre, 2005.

SCHMITZ, Pedro Ignacio et al. 0 projeto vacaria: casas subterrâneas no Planalto Rio-Grandense. Pesquisas. Antropologia, São Leopoldo, n. 58, p.11-106, 2002.

TEIXEIRA-PINTO, Márnio. IEIPARI: sacrifício e vida social entre os índios Arara. Curitiba: Editora da UFPR, 1997.

TOMMASINO, Kimiye. A ecologia dos Kaingang da bacia do rio Tibagi. In: MEDRI, Moacyr E. et al. (Ed.). A bacia do Rio Tibagi. Londrina: M. E. Medri, 2002. p. 81100 .

TOMMASINO, Kimiye; FERNANDES, Ricardo C. Kaingang. Enciclopédia dos Povos Indígenas. Instituto Sócio-Ambiental. 2001. Disponível em: <www.socioambiental.org/pib/epi/kaingang/print.htm>. Acesso em: 20 abr. 2004.

TOMMASINO, Kymiye; MOTTA, Lúcio Tadeu; NOELLI, Francisco Silva (Org.). Novas contribuições aos estudos interdisciplinares dos Kaingang. Londrina: UEL, 2004.

VIVEIROS DE CASTRO, Eduardo. Os pronomes cosmológicos e o perspectivismo ameríndio. Mana, Rio de Janeiro, v. 2, n. 2, p. 115-144, out. 1996. 